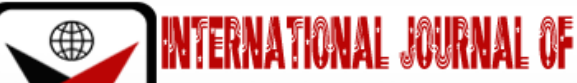

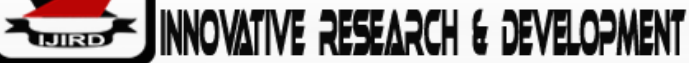

ISSN 2278-0211 (Online)

\section{A Case Study of the Curriculum Assessment Reform: The Student-Led Group Discussion in Learning Business Economics}

Minmin Shao
Teaching Assistant, School of Economics, Business Economics Teaching and Research Office,
Tongling University, China
Yuxiang Qiao
Xecturer, School of Law, Anhui University of Finance \& Economics, Bengbu, Anhui, China
Xiangqian Yang
Associate Professor, Institute of Finance and Public Management,
Anhui University of Finance \& Economics, China
Jiagang Guo
Lecturer, School of Business Administration,
Anhui University of Finance \& Economics, Bengbu, Anhui, China

\begin{abstract}
:
With the advancement of the course reform process in colleges and universities, the need is urgent for new ways of course assessments to the traditional assessment models. The ways of course assessment have been gradually diversified, becoming multi-staged to achieve different learning objectives. In order to better fit the current teaching climate with reducing assessment numbers and diversified course objectives, this paper studies the rationality of using group discussion as a meaningful component of the course assessment system. This research is based on the exploration of various course assessment methods that meet the applied talent training objectives, while using student-led group discussions as a medium-term classroom assessment to discuss and reflect on effects of the course assessments in learning business economics. We acknowledge that student-led group discussion is a kind of evaluation technique which is often used in the evaluation centre. This case study suggests to us that the use of this evaluation technique in the business economics curriculum assessment system can give rise to the betterment of students' comprehensive learning capability.
\end{abstract}

Keywords: Curriculum reform, curriculum assessment, business economics

\section{Introduction ${ }^{\mathrm{i}}$}

With the advancement of course reform processes in higher education, the necessity of a more dynamic course assessment methods reform is becoming increasingly prominent. The essence of innovations in the traditional teaching mode is more than innovating merely in the context of teaching, for which it is also necessary to make the corresponding innovations in the curriculum assessment. In September 2018, the Chinese Ministry of Education issued a notice to eliminate 'spam courses'i.e., those low-quality courses which have little essence and which for the most part are just for the formality of holding classes - which courses are termed in the Chinese context 'water courses'('水课').Instead, the ministry encouraged the higher education sector to create 'gold courses' ('金课'), requiring comprehensive rectifications of the order of undergraduate education and teaching while demanding stricter process management of teaching and learning.The ministry requires higher education institutions to reasonably improve the degree of academic challenges, increase difficulty of course curriculum, expand the depth of the curriculum, and effectively improve teaching quality of course curriculum.

It is necessary to effectively strengthen the learning process assessment, and increase the proportion of the process assessment in the total results of the course.It can be seen that the course assessment method will be diversified, in both procedural and quantifiable terms.This paper aims to demonstrate the disadvantages of traditional assessment methods, suggesting that traditional teaching methods cannot meet the requirements of diversified curriculum reform outcomes.To this end, this paper will discuss the rationality of the course assessment system, as well as how teachers as observersmust examine the comprehensive ability of students based on multi-angle, multi-index, and multi-level learning objectives in order to supplement the traditional course assessment methods. 


\section{Limitations of the Existing Curriculum Assessment Model}

The existing curriculum assessment methods have limitations such as having a single assessment form, single content and single evaluation mode ( $\mathrm{Li}, 2019$ ). The course assessment form tends to be the final examination or at least examination-oriented. In this single assessment mode, students see passing the examination as the goal, because the test scores are the only way to assess the teaching and learning of the curriculum. This will cause students to ignore more useful learning practices and process. They do not pay attention to the classroom learning, with the goal to only cope with the final exam as the purpose of learning and going to class. The content of the examination is usually based on textbook knowledges, while the question type is simplistic. This assessment mode cannot distinguish the difference between compulsory education and higher education. Furthermore, students' interests, their mastery and the comprehensive learning ability of the course content cannot be assessed.

The assessment method which is in the Chinese context called 'teachers setting examination papers and students forgetting everything after the examination' can no longer adapt to the speed of classroom teaching update in the Internet era.The evaluation methods based on the examination results cannot accurately reflect the students' learning and their mastery of the course knowledge. In some cases, students usually ignore class learning and stay up late all nights before the exam in order to pass the exam. For teachers, simply taking the final examination paper results as the only evaluation result is easy, but the method cannot well reflect the students' learning achievements.

With the advancement of the course reform process in colleges and universities, the applied talent training concept is promoted. With the application of online and offline mixed teaching mode, the traditional course assessment mode mainly focusing on final examination or examination can no longer meet the needs of curriculum reforms. In order to meet the purpose of building a 'golden class' and to adapt to the reform of classroom teaching methods, it is urgent to carry out the reform of the curriculum assessment mode in line with the curriculum reform.

\section{The Concept of Training Application-Oriented Talents and Reforming Curriculum Assessment Modes}

Different from the needs of technical and skilled talents in higher vocational colleges, higher education is going through the rapid developments and Chinese modern society and economy will put more emphasis on the systems of application-oriented training for undergraduate talents in relevant fields. This means that higher education emphasizes the application research ability and vocational development potential (Wu and Huang, 2014).The training of applicationoriented or applied talents should be guided by the cultivation of practical ability, adhering to the practice modes of the integration between industry and education and between school and enterprise. Instead of taking the single vocational education as the training goal, the concept of applied talent is also different from the talent training mode of researchoriented universities. From the concept of applied talent training, college curriculum assessments should pay attention to the systematic application of professional knowledge, independent research ability and future career planning ability.

With the highly applied business economics course, the course assessment should establish the concept of applied talent training, and pay attention to the investigation of students' comprehensive expression ability and knowledge application ability. Business economics has a professional orientation in economics and business, which aims to cultivate system master economics and business-related basic theory and practice skills. It requires students to be familiar with the modern market economy of business activities, to understand the basic theory of modern business, to have complete business knowledge and decision-making ability, to be able to do business analysis, and to master modern business practice skills. It will also require students to have high levels of foreign language skills and strong cross-cultural communication ability of the applied business profession. The existing research suggests that the training of business undergraduate talents should take the initiative to meet the needs of local economic and social developments, exploring teaching with application research and academic research. We should pay attention to the cultivation of students' practical ability, employment ability and entrepreneurial ability (Zhong and Wang, 2016).Therefore, the introduction of the assessment method with practical ability, employment ability and entrepreneurial ability training in the assessment of business economics course, is one of the important ways to meet the objectives and requirements of applied talent training concept.

\section{The Rationality of Taking a Student-Led Group Discussion as a Medium-Term Classroom Assessment}

Student-led group discussion is an evaluation technique that is originally mostly used for talent recruitment and human resource assessment. It is suitable to selecting candidates or candidates with leadership or marketing skills. The application scope of this kind of group discussion is becoming more and more extensive, which is not limited to the human resources assessment within enterprises. For example, it is also used in other selection processes such as campus recruitment and civil service examination in China. This technique simulates career scenarios to solve specific problems to facilitate the subject's comprehensive ability in a short period of time.

During group discussions, candidates will not be assigned a specific role, meaning that the organizer does do not specify who is the leader in the discussion, or specify a seat for each candidate. All candidates need to arrange their own seats and organize their own discussions. The size of groups for group discussion generally ranges from 4 to 8 people per group, and participants get the same information with everyone else. Group members need to propose a final solution to the examination questions combined with relevant information. The interviewer does not participate in the discussion process, who only observe the performance of each subject in the discussion (sometimes through special camera equipment) to score the various investigation elements of the subject, so as to judge their ability and quality level.

This kind of group discussion has the functions of both evaluation and diagnosis, which is widely used in career selection and is an efficient achievement-oriented assessment method. The introduction of such group discussions as an evaluation method is in line with the concept of college curriculum reform and application talent training. The assessment 
objectives discussed by the groups include many. For example, it is to test the comprehensive ability of the respondents, including the ability of organizational coordination ability, oral expression ability, debate ability / persuasion ability, communication ability, emotional stability, interpersonal skills, and non-verbal communication ability (such as facial expression, body posture, intonation, speed and gestures, etc.). It also tests their confidence, enterprising abilities, responsibility, flexibility, emotional control and behavioral styles, meeting the requirements of the applied talent training objectives. Moreover, the topics discussed by the student groups are diverse, and teachers can independently design the topics and content to be discussed combining the curriculum outline and teaching objectives to comply with the update of curriculum teaching content. In view of the extensive use of student-led group discussions in campus recruitments and civil service examination in China, making students familiar with and participate in this assessment mode in advance is conducive to students. Because it may help students to do a good job of career planning in advance, improve their application ability, and apply their professional knowledge to the discussion.

\section{Background of the Case Study}

This study was conducted in the School of Economics in Tongling University. Tongling University, located in Tongling City, Anhui Province in China, was founded in 1987, formerly known as Tongling Normal College and Tongling Finance and Economics College. In March 2002, the Ministry of Education approved the official upgrade to the undergraduate university, and renamed 'Tongling University'. Tongling University has edited and published an academic journal 'Tongling University Journal'. The campus of the college covers an area of about 890,000 square meters, the school building area of 320,000 square meters, the library contains 750,000 volumes, and the total value of teaching instruments and equipment is more than 70 million Yuan. The college has more than 750 faculty and staff, including more than 580 full-time teachers, nearly 200 professors and associate professors, more than 12,000 full-time college students, and more than 1,700 students in adult education. In 2003, the college acquired land of 680,000 square meters in Tongling Economic and Technological Development Zone to build a new school. Tongling University is an application-oriented undergraduate university with distinctive financial characteristics, mainly in economics, management, and the coordinated development of engineering, literature, science, art, law and other disciplines. Formerly Tongling Finance and Economics, it merged with Anhui Metallurgical Industry School and Tongling Normal School in 2000, and was upgraded to an ordinary undergraduate university in 2002. The school is the first demonstration of applied undergraduate universities in Anhui province, which was approved in 2015 by the Anhui local-applied-high-level-university-building-unit. In May 2018,it went through the Ministry of Education's undergraduate teaching work review. In September 2019, it was approved by Anhui province master degree awarded project unit. In April 2020, 'Tongling College Student Innovation Space' successfully selected into the nationalist, which become the only national student innovation space in Anhui province.

The School of Economics has a major undergraduate course in business economics. Business economics mainly studies the basic knowledge and skills in economy, business, trade, marketing and management, in order to understand the rules and practices, current status, development trends, and policies and regulations of Chinese and international trade. It also helps students tocarry out business analysis, business planning, business operation and business expansion. For example, these practical skills include attracting investment for enterprise projects, cost-benefit analysis of enterprise investment, follow-ups of potential customers, and facilitating the business negotiation between buyers and sellers before the transaction. We also provide professional training with social responsibility, practical ability, innovation, entrepreneurship and international visions. We encourage undergraduate students to engage in education and to master the basic business ability in enterprises, government and other departments. Students should be able to apply economic analysis and data processing methods, with modern economic and management concepts. They are expected to be competent for business practices. The major has promising employment prospects and enables economic analysis, forecasting, planning and economic management in integrated economic management, policy research, financial institutions and businesses. Students need to master the current situation and development trend of contemporary international cultural trade, be familiar with the common international cultural trade rules, practices and policies, and regulations of Chinese foreign cultural trade. They should understand the development characteristics and operation mechanism of cultural industry and can work in radio and television institutions or other cultural institutions, such as foreign economic and trade departments, enterprises and institutions and government agencies engaged in foreign cultural trade for the roles in management, research, distribution and planning.

In School of Economics, curriculum assessment is the test of students' 'learning knowledge, the feedback of learning effect, the evaluation of teachers'. It focuses on teaching effect and quality, and it is a comprehensive evaluation system. The nature and teaching characteristics of different courses are different, their teaching methods, and the course assessment methods will also change accordingly. Under the new situation, the talent training objectives and plan and curriculum construction should change accordingly. The assessment mode should also change in order to promote the development of students' quality and potential, as well as the coordinated development of knowledge, ability and quality. Under the background of information era today, the goal of curriculum assessment reform should be to stimulate students' ability to study independently and solve practical problems, to strengthen the evaluation of students' learning process, and to pay attention to the development of student personality and innovation ability cultivation. This way, the assessment can truly test students' learning results, and promote the reform of teaching methods and teaching content.

In student-led group discussions, there are generally five roles for candidates to be consciously played in, namely icebreaker, leader, coordinator, time controller and summarizer. The icebreaker refers to the first person to speak in a group discussion. In the group discussion, candidates are required to organise themselves from beginning to end. Generally speaking, the candidates do not know each other, so the first to speak often needs a certain level of courage. The icebreaker is the first to stand out in silence, often attracting the attention of the examiner who tend to give the icebreaker 
extra points.But icebreakers also bear some risks. Since icebreakers are the first to speak, they are the most noticeable to teachers. Therefore, if the icebreaker is fluent with a clear logic, they will attract the attention of the examiner in a positive sense. If the icebreaker is not fluent, too nervous or their logic is not clear, speaking up first is equivalent to a high-profile exposure of their own defects.

Leaders generally play a leading role in the whole process of the discussion. To play a successful leader is not to order others, but to use their own ability and charm to conquer the members of the group and examiners. In some group discussions, some candidates may think that as long as they issued orders to other candidates, they would be considered the leader. But this is not the case. If their ability is not very strong, or if they do not respect other candidates, then the members will not be unconvinced and will not cooperate, which will not play well with the examiner. Therefore, if the candidates intend to play the role of a leader, they must have full confidence in their ability and charm, and also have enough respect for other candidates.

Coordinators generally play a coordinating role in group discussions. Coordinators often function when differences arise. In case there is a disagreement, if members dispute, the group may leave a bad impression to the examiner. At this time, a coordinator is needed to narrow the gap between the opposing sides and encourage the group to form a unified conclusion without allowing the differences to influence the conclusion.

The role of the time controller is mainly to remind the progress in light with the time. Each stage should have a certain limit of time, but the examiner will not remind the examinee in the process. So, reminding the time becomes a necessary task. The role is relatively simple, but still requires attention. Time reminders cannot be too frequent, which should be effective and have a substantive effect.

The last role is the summarizer, which requires clear thinking and fluent expression. To summarize is to conclude the group discussion, with a necessary explanation of the differences in the discussion. The summarizer must keep in mind that the summary represents the group, not the individuals. So, the summary must be the result of the group discussion, not their own views which may be contrary to the group.

\section{The Case Study}

The practice of this course assessment reform takes the assessment of a business economics course at Tongling University as a case study. Student-led group discussion is introduced as the mid-term assessment into the course assessment system, aiming to investigate students' application ability and comprehensive quality of professional knowledge. Business Economics is a special major of the Ministry of Education. Since Tongling University successfully applied for business economics and its first enrolment in 2015, Tongling University has been continuously improving the innovative talent training system and professional curriculum system of business economics. Business Economics is a major course for students majoring in business economics. The course mainly covers two modules of economics principle and business management, which is suitable for students in business economics who have the foundation of microeconomics, macroeconomics and business planning in the early stage. Students' thinking is divergent and active, which is suitable for classroom brainstorming, case analysis and solving the corresponding business economics problems under the guidance of teachers.

This practice enables students to understand the latest business dynamics and helps improve problem solving and employment and entrepreneurship ability. It increases learning interests and guides independent learning, diversity and is in line with whole-process assessment methods. Students can participate in subject-related competitions, innovation and entrepreneurship training programs, and various business planning projects.

This classroom assessment practice includes three links: preliminary preparation, assessment implementation and assessment effect evaluation. Preliminary preparation includes the setting of the assessment objectives, the design of the content and the preparation of the assessment task book. The assessment implementation includes the implementation of the classroom assessment process, the report of the assessment results, and actively using modern information technology in the implementation course to improve the assessment implementation process. The evaluation of the classroom assessment effect relies on the network information technology, such as the questionnaires to collect the relevant evaluations and suggestions of the assessed students on the assessment effect.

\subsection{Classroom Assessment Preparation}

In the week before the implementation of the classroom assessment task, students were prepared and given relevant information, including assessment objectives, assessment content, discussion topics, process and related matters needing attention. This aims to let the students be clear about the classroom assessment objectives, content, student groups and evaluation standards in order to actively participate in the classroom assessment and standardize group discussion implementation process. A questionnaire survey of 63 students in business economics through learning software showed that $48.7 \%$ and $51.3 \%$ of the students were very clear or clear about the contents and requirements of the classroom assessment, respectively. None of them was unclear. About $70.3 \%$ of the students indicated that the teachers were fully prepared for the class assessment, and none of the students was insufficiently prepared for the class assessment.

The evaluation criteria are sufficient and balanced. These includehow much the students are actively involved, how many times of effective speeches they have made; how many disputes in the group and regulating disputes within the group. These also include the ability to create an atmosphere in which all speakers want to speak, and finally making everyone reach a consensus. Students are also examined on how many times they put forward their own opinions and plans, their ability to dispute and support in the group discussions. The examiner also observes whether the candidates listen to others and respect each other and their sensitivity of others' verbal responses and emotional responses, etc. 
In terms of the format of questions, five forms of questions were used. First, we used open questions. As the name suggests, the answers to these questions are open to everyone's own opinions using their own words. The type of questions mainly investigates whether the examinee is comprehensive and whether their thinking is clear with new views and opinions. Second, we used dilemmas. Dilemmas let candidates choose one of two answers with pros and cons.This type of questions mainly investigates the examinee' analysis ability, language expression ability and persuasion. Third, we also used multiple choice questions. These questions let candidates choose several of the effective or arrange the importance of alternative answers, mainly examining the ability to analyze the essence of the problem and grasp the essence of the problem. Fourthly, we used practical problems. These problems give candidates some materials, tools or props to use and process in order to let them design some object designated by the examiner. These problems mainly investigate the initiative and cooperative ability and practical skills.Finally, we used resource competition problems. Such problems are applicable to the designated role in the group discussion, which is to allow the candidates in the same status to allocate the limited resources. This is to investigate the candidates' language expression ability, problem analysis ability, summarize ability, speech enthusiasm and response sensitivity, etc.

\subsection{Classroom Assessment Implementation}

Before the assessment began, students are arranged based on the randomized list in the task sheet, and two students were assigned as observers of each group. Taking the simulation of enterprise recruitment as the premise of assessment, two observers simulate the recruitment of the enterprise. Students who participate in the discussion need to organize the discussion according to the characteristics and needs of the required positions. Teachers and observers do not participate in the discussion process and will not play any role. Group discussion topics and evaluation standards by the observers of each team is to communicate to the group. Discussion topics should meet the requirements of the business economics module. Finally in the form of the group, they should summarize for the teacher to maintain the order of the discussion and observe the whole classroom discussion.

For the implementation process, $59.5 \%$ of the students thought that the classroom assessment was organized orderly, $40.5 \%$ thought that the classroom assessment organization was relatively orderly, and no student thought that the organization was disorderly or inappropriate in the discussion process. As for the effect of the implementation of the group discussion, $70.3 \%$ of the students believed that the atmosphere of the classroom assessment was very active, and 83.8\% believed that the interaction by the teacher with the students during the assessment process was very reasonable.The topic of discussion is in line with the latest social and economic updates and the research direction of business economics, which greatly stimulated the enthusiasm of students to participate andwas helpful to the whole assessment process.

\subsection{Evaluation and Suggestions Regarding the Classroom Assessment}

The learning software was used to publish questionnaires to collect students' evaluation of the effect of the classroom assessment. Over $62 \%$ of students agreed that the classroom assessment can inspire students to think and cultivate students' practical ability of students. About half of the students agreed that the classroom assessment was very rewarding and very fruitful. About $67.6 \%$ of students thought this classroom assessment method as a necessary link in the classroom assessment of business economics courses. When soliciting the opinions and suggestions of the tested students on the classroom assessment, some students proposed that the classroom setting is not conducive to the group discussions, and the school should provide a roundtable discussion venue'. Some students also thought that 'the discussion of component topics is too scattered that the whole class should discuss unified topics in groups'. From the questionnaire results, the students who participated in the discussion and assessment of the group discussions were more concerned about the assessment results, and still actively put forward their own opinions and suggestions on the assessment methods.

\subsection{Reflection}

First, there was confusion in the discussion process because some students were not familiar with the assessment process. Students need to be very familiar with the group discussion process in order to participate well.Under this premise, some students are required to take the active role as a leader.Due to the large number of students in the class, there is no guarantee of the order in the discussion, and there will be a certain confusion.For example, in some groups no one was willing to act as the role of the leader to organize the group discussion, while some groups did not understand the purpose of the assessment, etc.

Second, it might be a concern that the discussion process cannot be observed throughout the assessment period. Although observers were set up in each group, fully recorded monitoring notes will be required for the final examiner, i.e., the course teacher to ensure that the performance of each student can be evaluated.Due to the large number of students, the large classroom and the large number of groups, there were certain restrictions on how many observations the course teachers could personally make.If we cannot ensure that each student is observed, there will still be some one-sided and unfair evaluation of some students.

Finally, the results of the discussion lack comprehensiveness of representation of all students in the group. The final discussion results of the students were reported in the group, but the results of the group reports often reflect certain students' thoughts and cannot reflect each student's ideas. The evaluation of the course assessment is ultimately based on individuals, so the result briefing meeting by group may cause individual performance distortions. There were high scores for leaders, but the performance of the team members was often underestimated.This also has a certain negative impact on the fairness of the assessment method. 


\section{Conclusion and Suggestion}

From the perspective of the implementation results, it is somewhat practical to incorporate the group discussion into the business economics course assessment system. From the perspective of the assessment effect, students' participation and comprehensive knowledge application ability have. been greatly improved. On the one hand, this increased the difficulty of the course assessment. On the other hand, this also made the classroom interesting and interactive, which we can use to try to promote as a whole course assessment system. However, in the specific implementation process, there were also problems such as relatively chaotic organization and the lack of comprehensive discussion results. In this paper, the following suggestions are made to improve the assessment method of this course.

\subsection{Strengthen the Design of Assessment Methods, and Prepare the Corresponding Assessment Outline}

Preparation for classroom assessment in advance requires at least one teaching cycle to strengthen the assessment design and prepare corresponding assessment outline. It provides relevant instructions and training for students to familiarize themselves with and adapt to the content, method and process of group discussion.

\subsection{Use Technology in the Classroom}

The development of modern teaching technology provides support to the curriculum implementation. Apply modern teaching technologies such as electronic video recording to shoot and archive students 'discussion process may help.

\subsection{Diversify Evaluation Methods}

We can use more evaluation sources, such as peer assessments and self-evaluation. Diversified evaluation methods should be combined to avoid the situation where the teacher decides all.

\section{Funding Information}

This research is funded by: Anhui Education Department, Project No. 2020sjixm09, Project No. 2020wyxm179 and Project No. 2019ylzy01. For further details, please contact corresponding author Jiagang Guo atbradgjg@163.com

\section{References}

i. Li Xiaoyun. Reform the professional curriculum assessment method to cultivate outstanding news and communication talents [J].Education modernization, 2019,6 (75): 14-16.

ii. Zhong Binglin, Wang Xinfeng. Analysis on the Practice ath of Local Undergraduate Colleges in China [J]. Higher Education Research, 2016,37 (10): 19-24.

iii. Wu Zhongjiang, Huang Chengliang.The connotation of applied talents and applied undergraduate talents training [J].Higher Engineering Education Research, 2014 (02): 66-70.

\section{References in Chinese (Their Original Language)}

i. 李晓云.改革专业课程考核方法培养卓越新闻传播人才[J].教育现代化,2019,6(75):14-16.

ii. 钟秉林,王新凤.我国地方普通本科院校转型发展实践路径探析[J].高等教育研究,2016,37(10):19-24.

iii. 吴中江,黄成亮·应用型人才内涵及应用型本科人才培养[J].高等工程教育研究,2014(02):66-70.

\footnotetext{
'All translations are our translations unless otherwise specified. For more details, please contact the corresponding author Jiagang Guo
} atbradgjg@163.com 